\title{
El juego de las locuras: Ifigenia, San Pablo y el pensamiento crítico
}

Franz Hinkelammert

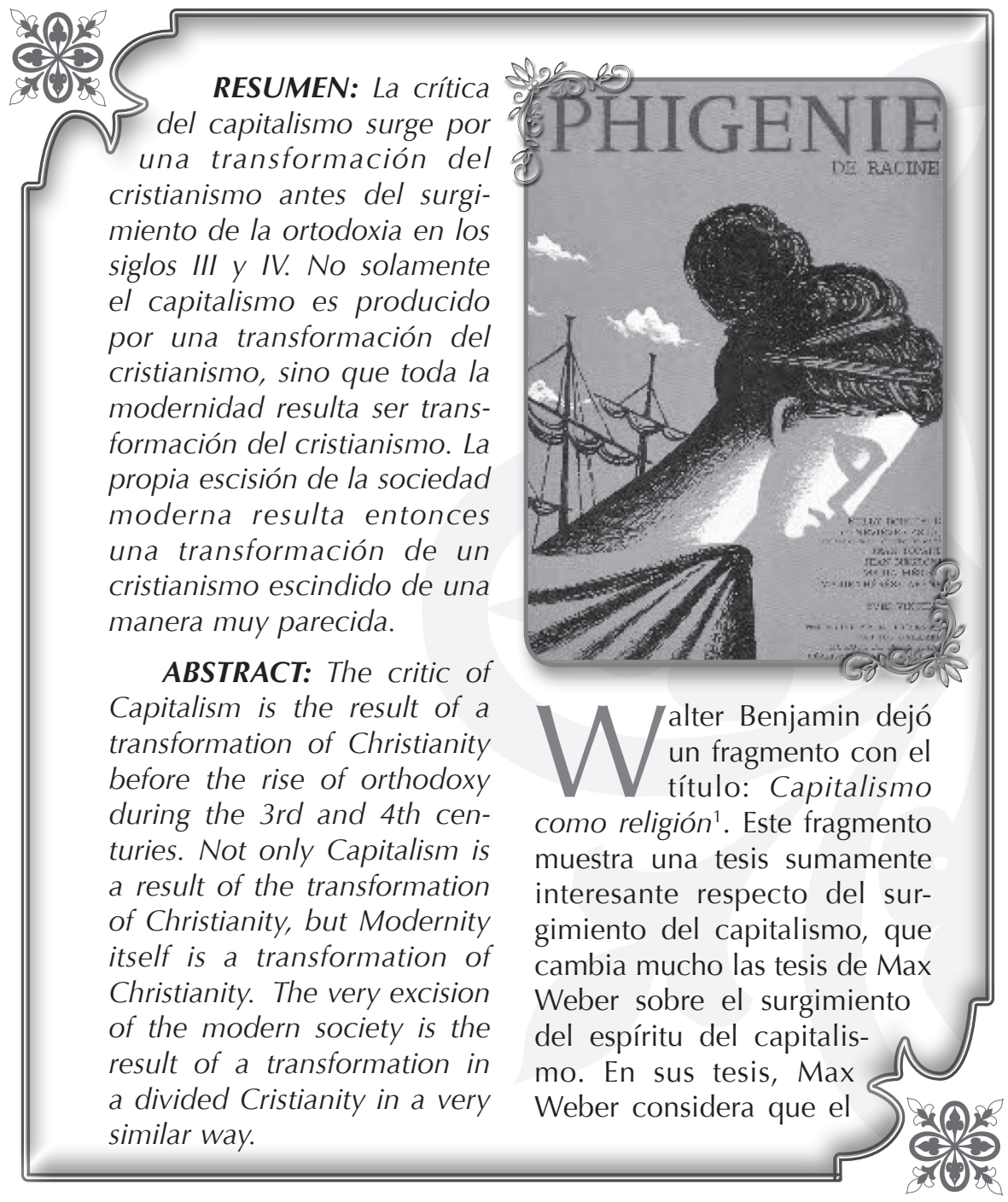


cristianismo -especialmente en su forma calvinista y puritana- ha sido un elemento que ha promovido el surgimiento del capitalismo, para ser superado después por un proceso de secularización.

Walter Benjamin, en cambio, presenta la tesis de que el papel del cristianismo ha sido diferente e incluso más decisivo. Considera y también demuestra, que el capitalismo surge por una transformación de la ortodoxia cristiana, que en forma secular sigue operando en el interior del capitalismo con el resultado de que el mismo capitalismo aparece una religión de procedencia cristiana, aunque sea expresado en forma secular.

La tesis está convincentemente presentada. Sin embargo, tiene una limitación. El mismo Benjamin habla de una transformación de la ortodoxia cristiana en capitalismo. Si nos limitamos a eso, el cristianismo parece agotarse en el origen del capitalismo y nada más.

Sin embargo, me parece, que hay más. Si analizamos la misma transformación del cristianismo en ortodoxia cristiana, el significado del cristianismo se amplía. Preguntándonos cual es este cristianismo que es transformado en ortodoxia, podemos ver, que no solamente el capitalismo es transformación de la ortodoxia cristiana en capitalismo, sino que a la vez la crítica del capitalismo surge por una transformación del propio cristianismo antes del surgimiento de la ortodoxia en los siglos III y IV y que sobrevivió más bien como la herejía del propio cristianismo ortodoxo.

En este caso, no solamente el capitalismo es producido por una transformación del cristianismo, sino que toda la modernidad, como surge a partir del siglo XVI, resulta ser transformación del cristianismo, tanto el capitalismo como también la crítica del capitalismo y la búsqueda de nuevas formas de organizar la sociedad, que aparecen sobre todo con los movimientos socialistas. La propia escisión de la sociedad moderna resulta entonces transformación de un cristianismo escindido de una manera muy parecida.

Se puede hablar de un juego de locuras, que aparece. En lo siguiente quiero desarrollarlo.

\section{El juego de locuras y su historia}

V ivimos un tiempo de locuras; pero para estas locuras vale lo que dice Hamlet: Aunque sea locura, método tiene. Hay que ver nuestras locuras a la luz de una historia de locuras y de reproches de locuras. Quiero ver, por tanto, nuestras locuras en el contexto de algunos elementos de esta historia. 
Hay juegos de locura. Pero lo que son, es mejor mostrarlo no por definiciones, sino contando los cuentos de las locuras y los juegos mutuos en los cuales aparecen. Quiero partir de la Orestíada griega.

Hay un juego de locuras entre Agamenón, Clitemnestra e Ifigenia (sea según Esquilo o Eurípides), aunque sea todavía parcial. Goethe lo hace desaparecer; pero no se completa.

Esta historia de Ifigenia muestra el límite de la conciencia griega. Esquilo, en su trilogía sobre la Orestíada, cuenta el sacrificio de Ifigenia hecho a mano de su padre Agamenón. El ejercito griego había salido para su guerra de la conquista de Troya, pero en el camino se quedó paralizado, porque no había viento para seguir. Agamenón preguntó a la diosa Artemis-Diana por la razón y ella le comunicó, que solamente habría viento de nuevo, si sacrificaba su hija Ifigenia a la diosa. Agamenón hizo el cálculo que correspondía. Mandó a sacrificar su hija. El sacrificio era útil, por tanto necesario. Mandó a los verdugos, pero Ifigenia se resistió. Maldijo a su padre, les gritó asesinos a sus verdugos y pataleó con toda fuerza hasta que la callaron dándole muerte en el altar de sacrificio.

El texto deja claro lo que también entendía el público: era loca Ifigenia, Agamenón era el sensato. Toda la máquina de guerra estaba movilizada, no quedaba razonablemente otra salida que la muerte de Ifigenia en el altar de sacrificio. $Y$ brillaban las riquezas de Troya y su brillo se veía desde muy lejos.

Desde el punto de vista del cálculo de utilidad, Ifigenia tenía que morir. Era útil su muerte y por tanto necesaria. Eso dice la sabiduría de este mundo. Es como dijo el general Massis, general en la guerra de Argelia: la tortura es útil, por lo tanto, necesaria. Obviamente, Ifigenia se había vuelto loca. Sin embargo, es de hecho la gran sabia en este baile de la muerte. Ella es la razonable, no Agamenón, que sufre la locura de la sabiduría de este mundo, para usar la palabra de San Pablo. La misma Ifigenia lo hace ver como un loco.

Pero otra solución no cabe en el pensamiento de este tiempo. Esquilo muestra solamente la locura de Ifigenia, no se le ocurre completar el juego de locuras para ver que Ifigenia, la loca, era la sensata y que era Agamenón el loco asesino.

Eurípides lleva este argumento mucho más lejos que Esquilo. Se considera a Esquilo más bien como conservador, mientras se llama a Eurípides el autor de la Ilustración griega. La historia que cuenta Eurípides es, hasta el momento del sacrificio, la misma que contó Esquilo, pero Ifigenia ha cambiado. Es ahora una mujer que ha entrado en razón y acepta su muerte. Dice: 
Madre, escúchame: veo que te indignas en vano contra tu esposo, ...pero tú debes evitar las acusaciones del ejército...: resuelta está mi muerte, y quiero que sea gloriosa, despojándome de toda innoble flaqueza. ... la Grecia entera tiene puestos en mí sus ojos, y en mi mano está que naveguen las naves y sea destruida la ciudad de los frigios.... Todo lo remediará mi muerte, y mi gloria será inmaculada, por haber libertado a la Grecia. Ni debo amar demasiado la vida, que me diste para bien de todos, no solo para el tuyo. Muchos armados de escudos, muchos remeros vengadores de la ofensa hecha a su patria, acometerán memorables hazañas contra sus enemigos, y morirán por ella. ¿Y yo sola he de oponerme? ¿Es acaso justo? ¿Podremos resistirlo? Un solo hombre es más digno de ver la luz que infinitas mujeres. Y si Diana pide mi vida, ¿me opondré, simple mortal, a los deseos de una diosa? No puede ser. Doy, pues, mi vida en aras de la Grecia. Matadme, pues; devastad a Troya. He aquí el monumento que me recordará largo tiempo, esos mis hijos, esas mis bodas, esa toda mi gloria. Madre, los griegos han de dominar a los bárbaros, no los bárbaros a los griegos, que esclavos son unos, libres los otros.

Se nota que el texto está escrito e inventado por un hombre. Estoy convencido de que jamás ninguna mujer inventaría una barbaridad tal.

Sin embargo, el lugar de la loca principal, que en Esquilo tiene Ifigenia, lo toma ahora Clitemnestra, su madre. Con furia se dirige a Agamenón y le grita que es un simple asesino. Todos la condenan como loca, y de primera la propia Ifigenia, tan ilustrada como es ahora.

La loca, ahora Clitemnestra, es la sensata, pero no hay lugar para verla como tal. Clitemnestra rompe con Agamenón y cuando Agamenón vuelve de su guerra, lo mata. Aunque no comparto completamente las tesis de Walter Benjamin sobre la violencia santa, éste tendría que Ilamar esta violencia de Clitemnestra violencia santa, heilige Gewalt $t^{2}$. Clitemnestra es ahora la sensata, pero la cultura del tiempo no permite ni verlo. Es loca.

Esta forma que da Eurípides al sacrificio de Ifigenia, tiene historia. En la ilustración del siglo XVIII aparecen muchas obras sobre Ifigenia. Todas coinciden con la postura de Eurípides en relación al sacrificio de Ifigenia. Las Ilustraciones se entienden una con la otra. 
El drama más conocido es el de Goethe, que otra vez interpreta a Ifigenia yendo más lejos todavía que Eurípides. Según el mito griego, la diosa salva la vida de Ifigenia, sin que los griegos lo notaran y se la lleva a la isla de Tauris. Eurípides asume este resultado en otro drama, en el cual Ifigenia aparece como la sacerdotisa en la dicha isla. Pero ahora está furiosa. Quiere venganza por su muerte. Sacrifica a cualquier griego que aparezca en la isla. Ahora tiene la furia, que en Esquilo tiene antes de ser sacrificada; pero es furia de venganza, no de protesta.

Goethe en su drama Ifigenia en Tauris, corrige eso. Ifigenia también es sacerdotisa, pero es un ángel de la paz. Clitemnestra sigue siendo la loca e Ifigenia sigue aceptando su sacrificio por su padre Agamenón. Pero ahora el sacrificio resulta en la búsqueda de la paz, para que no haya más sacrificios humanos. Esta solución es más ilustrada todavía que la de Eurípides.

Es muy evidente que Goethe en términos seculares cristianice a Ifigenia. Ella es ahora un alter Cristo, en sentido de la ortodoxia cristiana, sin que Goethe haga la más mínima alusión a ello. Lleva a su término una interpretación que aparece ya antes en la propia tradición cristiana, según la cual esta Ifigenia de Eurípides, con su actitud frente a su sacrificio es un antecedente para la actitud con la cual el propio Jesús aceptó ser sacrificado en la cruz aceptando la voluntad de su padre, que querría su muerte para salvar -y conquistar - la humanidad.

Esta Ifigenia cristianizada en términos completamente seculares interpreta bien la actitud de la ilustración europea, que la aceptó sin tener siquiera dudas, pero no solamente en la tradición liberal. En 1936, durante las purgas estalinianas, se presentó la Ifigenia de Goethe en un teatro central de Moscú. El mensaje es: del asesinato - visto como sacrificio humano- resulta la paz. No resultaría sorprendente si hoy se presentara esta misma obra en Nueva York. La necesitan urgentemente ${ }^{3}$.

Efectivamente, la teología ortodoxa interpreta el sacrificio de Jesús de una manera casi idéntica a la interpretación del sacrificio de Ifigenia en Eurípides con los cambios correspondientes al cambio de la situación.

Sin embargo, es solamente parcialmente idéntica. En la ortodoxia cristiana también aparece otro Cristo con furia por su crucifixión. Es furia en contra de sus crucificadores. Es análogo a la Ifigenia en Tauris de Eurípides. Pero Goethe no hace presente este lado de Ifigenia.

En un texto famoso, Bernardo de Claraval nos presenta a este Cristo enfurecido: 
Mas los soldados de Cristo combaten confiados en las batallas del Señor, sin temor alguno a pecar por ponerse en peligro de muerte y por matar al enemigo. Para ellos, morir o matar por Cristo no implica criminalidad alguna y reporta una gran gloria. Además, consiguen dos cosas: muriendo sirven a Cristo, y matando, Cristo mismo se les entrega como premio. El acepta gustosamente como una venganza la muerte del enemigo y más gustosamente aún se da como consuelo al soldado que muere por su causa. Es decir, el soldado de Cristo mata con seguridad de conciencia y muere con mayor seguridad aún ${ }^{4}$.

Aparece el Cristo que persigue con furia a sus crucificadores, viéndolos en todas partes, especialmente como judíos. Sus cristianos, al conquistar el mundo, ven siempre en los sometidos crucificadores de este Cristo y los aniquilan para vengar la crucifixión, adueñándose en el camino de sus países, sus riquezas y haciéndolos esclavos suyos. En forma secular les siguen los burgueses y hasta los estalinistas.

Cuando hoy vemos escrito en los autos: Cristo viene, no se trata de una promesa de un futuro feliz. Se trata de una amenaza: si no te pones en la lid de Cristo, vas a ser aniquilado. $\mathrm{Y}$ los que ponen estos anuncios, estarán salvos y mirarán con gusto este aniquilamiento justo.

Este Cristo es una analogía de la Ifigenia de Eurípides después de su sacrificio, en donde se empeña como sacerdotisa furiosa que ejerce su venganza con los griegos que visitan su isla sacrificándolos en el altar de sacrificios.
La Ifigenia de Goethe no muestra esta Ifigenia furiosa. Muestra a Ifigenia en la isla Tauris como una sacerdotisa de la paz, que erige un Edén de los derechos humanos como fueron pronunciados en su tiempo a partir de la Ilustración del siglo XVIII: libertad, igualdad y Bentham. Esconde los infiernos que se están produciendo en nombre de estos mismos derechos humanos en el mundo entero.

El brillo de las riquezas de Troya sigue aún hoy. Es ahora el brillo de las riquezas petroleras del mundo entero, pero especialmente hoy del Irak y del Irán. Se sacrifica igualmente, y al presidente Bush el mismo Dios en el cielo le pide efectuar el sacrificio. Las Ifigenias sacrificadas abundan. Y las Clitemnestras, que hablan del asesinato de parte de los nuevos Agamenón y que, por tanto, declaran quién es el asesino, son tratadas como locas igual que siempre. 
Podríamos construir, sin embargo, ficcionalmente otra postura de Agamenón. Si hubiera sido razonable, habría desistido de la guerra e interpretado la calma del viento como voluntad de la diosa de volverse pacíficamente a su casa. Claro, en el caso de que hubiera querido eso, el propio ejército griego lo hubiera declarado loco a él mismo. No habría sobrevivido. Pero su muerte habría sido un testimonio, no un sacrificio. En este caso, se hubiera dado un antecedente efectivo de la muerte de Jesús en la cruz, que tampoco es sacrificio, sino testimonio. Habría caído en la locura divina y lo que San Pablo llama la sabiduría de Dios.

Igualmente, como patriarca de una sociedad patriarcal, sería gravemente sospechoso si mostrara la debilidad humana de dejarse seducir por su mujer Clitemnestra. Habría caído en la trampa de la mujer, como Adán cayó en la trampa de Eva seducido por ella a comer del árbol de la ciencia del bien y el mal. También en el caso de Clitemnestra, ella habría seducido a Agamenón para comer del árbol de la ciencia del bien y el mal y él habría desistido del crimen del asesinato de su hija y de la conquista de Troya ${ }^{5}$.

Pero esta ficción no es pertinente para la sociedad griega de este tiempo. Estaría fuera de su conciencia posible.

Sin embargo, en este caso se completaría el juego de las locuras.

\section{San Pablo y la locura}

$\mathrm{P}$ ero solamente en este caso aparecería el juego completo de las locuras y veremos cómo San Pablo lo hace presente. La razón es que en los textos griegos mencionados rige simplemente lo que San Pablo Ilama la sabiduría de este mundo y su cálculo irrestricto de la utilidad, frente al cual todo lo otro es locura. Algo como la sabi- duría de Dios, de la cual habla San Pablo, frente a la cual esta sabiduría del mundo es locura, no se asoma. ${ }^{6}$

Por eso quiero hacer presente el juego de locuras como lo elabora San Pablo en los primeros capítulos de su primera carta a los Corintios ${ }^{7}$.

San Pablo se introduce diciendo:

Porque no me envió el Mesías a bautizar, sino a predicar la Buena Nueva. Y no con palabras sabias, para no vaciar de contenido la cruz del Mesías. 1 Cor. 1,17 
Lo que hace presente San Pablo es un proyecto de liberación. Aunque es activo para la iglesia, no se entiende al servicio de la iglesia, sino del proyecto mesiánico de la Buena Nueva. Entiende que la misma iglesia está al servicio de este proyecto y no al revés.

\begin{abstract}
¿Acaso no dejó Dios a la vista la locura de la sabiduría del mundo? De hecho, como el mundo mediante su propia sabiduría no conoció a Dios en su divina sabiduría, quiso Dios salvar a los creyentes mediante la locura de la predicación. 1 Cor. 1,20-21
\end{abstract}

La palabra "entonteció" (en vez de dejar a la vista la locura), que la traducción de la Biblia de Jerusalén usa, no dice lo que debe decir. Tendría que decir: dejó a la vista la locura, reveló la locura. Traductor-traidor. Pablo no mostró la sabiduría del mundo como tontería, no "entonteció". Los sabios de este mundo para San Pablo no son nada de tontos. Son efectivamente sabios, hasta son grandes genios. La locura, de la cual habla San Pablo, no tiene el sentido de una ofensa, sin es una caracterización. Pero su sabiduría puede ser locura, y a los ojos de la sabiduría de Dios lo es. Para el ser humano lo es, si ve a través de los ojos de Dios. Y con los ojos de Dios ve en el espíritu. Por eso, locura no impide inteligencia, ni sabiduría. La sabiduría que aparece entonces es la sabiduría de este mundo, pero al ser loca, la inteligencia o la sabiduría están dislocadas, están fuera de su lugar. Por eso es locura a la luz de la sabiduría de Dios.
Detrás hay probablemente una experiencia personal de Pablo en su visita a Atenas y su presencia en el Areópago. Chocó con los filósofos -epicúreos y estoicos- y ellos se rieron de él y lo trataron de charlatán. Es decir, lo encontraron como loco. (Hechos 17, 16-34) El punto clave para eso es la predicación de la resurrección de parte de Pablo. Pablo ahora invierte eso y desemboca en su juego de locuras: a la luz de la sabiduría del mundo la sabiduría de Dios es una locura, y a la luz de la sabiduría de Dios la sabiduría del mundo es una locura. Su experiencia la generaliza en este juego de locuras.

Pero lo hace frente a otro conflicto, que es un conflicto en la comunidad cristiana de Corintio. Es un conflicto por la institucionalización de la iglesia y por tanto, por el acto del bautismo: 
Porque, mientras haya entre vosotros envidia y discordia, ¿no es verdad que sois carnales y vivís a lo humano? Cuando dice uno "Yo soy de Pablo" y otro "yo soy de Apolo" ¿no procedéis a modo humano? 1 Cor. 3, 3-4

A eso se refiere, cuando insiste en que no ha venido para bautizar, sino para predicar la Buena Nueva. Corintios pierden el proyecto para luchar por personas y por su poder. Y pronto sintetiza lo que es el núcleo de la Buena Nueva: que Dios eligió lo loco, lo débil, el plebeyo y despreciado, y afirma lo que no es frente a lo que es, para dejarlo en la nada. Lo que ve, es la institucionalización de la comunidad con sus luchas de poder, que arrasan con el proyecto. Es la sabiduría del mundo y de los jefes de este mundo, a la cual contesta:

¡Nadie se engañe! Si alguno entre vosotros se cree sabio según este mundo, vuélvase loco, para llegar a ser sabio; pues la sabiduría de este mundo es locura a los ojos de Dios. 1 Cor. 3, 18-19

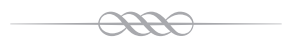

Y concluye:

Así que, no se glorié nadie en los hombres, pues todos son vuestro: ya sea Pablo, Apolo, Cefas, el mundo, la vida, la muerte, el presente, el futuro, todo es vuestro; y vosotros, del Mesías y el Mesías de Dios. 1 Cor. 3, 21-23

Viene entonces a hacer presente lo que es esta sabiduría de Dios. Primero dice lo que no es:

Así, mientras los judíos piden signos y los griegos buscan sabiduría, nosotros predicamos a un Mesías crucificado: escándalo para los judíos, locura para los gentiles: mas para los llamados, lo mismo judíos que griegos, un Mesías, fuerza de Dios y sabiduría de Dios 1 Cor. 1, 22-24 
Sigue con lo que es:

Porque la locura divina es más sabia que los hombres, y la debilidad divina, mas fuerte que los hombres. 1 Cor 1,25

La locura divina está en los seres humanos, aunque Dios la tenga tam- bién. En los seres humanos está por el espíritu (que sopla donde quiere):

¡Mirad, hermanos, quiénes habéis sido llamados! No hay muchos sabios según la carne ni muchos poderosos ni muchos de la nobleza. 1 Cor 1,26

Sabios según la carne son los sabios de la sabiduría del mundo, que es locura a los ojos de la sabiduría de Dios. Son también Platón y Aristóteles, y se puede extender hasta Heidegger. (Están en un lugar que no corresponde. En alemán se- ría verrückt: loco como dis-locado, ver-rückt)

Entonces San Pablo resume lo que es la sabiduría de Dios de la Buena Nueva. Se trata de la clave de toda la posición de San Pablo:

Ha escogido Dios más bien a los locos del mundo para confundir a los sabios. Y ha escogido Dios a los débiles del mundo para confundir a los fuertes. Lo plebeyo y despreciable del mundo ha escogido Dios; lo que no es, para reducir a la nada lo que es. 1 Cor. 27-28

Eso implica la dialéctica de lo que es y lo que no es. El ser -lo que es - es reducido a la nada, y lo que no es, es lo de que se trata. Es como en el cuento infantil: El emperador queda sin vestido.

Ese es el punto de vista que permite la orientación por medio de la verdad. (es lo velado, desvelado por la verdad)
Lo que ha escogido Dios, es — en el lenguaje del dadaísta Picabia- lo indispensable que es inútil. Eso es lo espiritual.

De él (Dios) viene que estéis en el Mesías Jesús, al cual hizo Dios para nosotros sabiduría de Dios, justicia, santificación y redención... 1 Cor. 1,30 
En 1 Cor 27-28 San Pablo ha justicia, santificación y redención. sintetizado esta sabiduría de Dios con su especificidad. De ella sigue Pero la sabiduría de Dios es el núcleo de todo. Por eso puede seguir:

Pues no quise saber entre vosotros sino al Mesías Jesús, y éste crucificado. 1 Cor. 2,2

Este Mesías Jesús encarna un proyecto para el mundo.

Sin embargo, hablamos de sabiduría entre los perfectos, pero no de sabiduría de este mundo ni de los jefes de este mundo, abocados a la ruina, sino que hablamos de una sabiduría de Dios, misteriosa, escondida, destinada por Dios desde antes de los siglos para gloria nuestra, desconocida de todos los jefes de este mundo - pues de haberla conocido no hubieran crucificado al Señor de la Gloria-. 1 Cor. 2, 6-9

Toda esta cita es muy importante para ubicar lo que para Pablo es la sabiduría de Dios. La vincula con la responsabilidad por la crucifixión de Jesús. Jesús fue crucificado por las autoridades, los jefes, de este mundo. Lo que se sobreentiende en San Pablo es, que lo hacen en cumplimiento de la ley. Ellos lo hacen, desconociendo la sabiduría de Dios. La palabra desconocer aquí no se refiere a un saber. Se refiere a un reconocer y un asumir. Pablo ya ha dicho, lo que es la sabiduría de Dios: que en los débiles está la fuerza, que ellos por tanto, son los importantes, que esta sabiduría tiene predilección por lo plebeyo y lo despreciado y que juzga a los que es desde lo que no es. Eso es la sabiduría de Dios,, que es: mis- teriosa, escondida, destinada para "gloria nuestra". Por ser encarnada en Jesús, se mata a Jesús por no reconocer esta verdad. Enfrentan a muerte a la sabiduría de Dios, la locura divina.

Cuando, a partir del siglo III y IV, se impone la ortodoxia -el Termidor del cristianismo, se margina esta interpretación de la crucifixión y sus responsables. Cuando se cristianiza el imperio, el imperio imperializa al cristianismo. La interpretación de parte de San Pablo se hace insoportable: si los jefes de este mundo y sus leyes, que incluyen al propio emperador, son los responsables de la crucifixión de Jesús, había que buscar otros crucificadores. Las frases correspondientes de San Pablo prácticamente 
no se citan más y son tratadas como frases irrelevantes.

San Pablo denuncia a los crucificadores, que son los jefes de este mundo. Pero les concede que actúan según la sabiduría de este mundo, lo que implica que actúan en nombre de la ley. Son ciegos, pero no están sin razones. Hay conflicto, pero el conflicto es con aquellos, de los cuales dice en la carta a los Romanos, "aprisionan la verdad en la injusticia". En este sentido son ideólogos cegados por su ideología. No saben lo que hacen, desconocen la sabiduría de Dios y la rechazan. Pero lo hacen en nombre de una sabiduría del mundo. No es maldad que explica la crucifixión, sino la estrechez e inclusive la locura de la sabiduría de este mundo.

Los nuevos crucificadores, sin embargo, son los judíos. Se trata de un antijudaísmo cristiano que arranca desde los siglos III y IV. Pero como crucificadores ahora son vistos como contrarios de lo que para San Pablo eran los crucificadores. Los judíos ahora son considerados como crucificadores sin razones. Actúan, vistos desde esta ortodoxia, por pura maldad. Son judíos "pérfidos" y en la Semana Santa ahora se reza por y en contra de estos judíos "pérfidos". Los judíos ahora son vistos como maldad pura, obsesionados por el poder y por su soberbia. No tienen razones. Por tanto no actúan tampoco en nombre de ninguna sabiduría de este mundo. Por tanto, el poder puede exterminarlos.
En occidente se ha mantenido hasta hoy esta imagen del enemigo por exterminar, sea éste judío, comunista, trotskista, terrorista o lo que sea. Inclusive se repite en las condenas de la teología de la liberación en cuanto que ella considera como su centro lo que San Pablo Ilama la sabiduría de Dios y la locura divina.

Esta transformación de la interpretación del crucificador entre el siglo I y los siglos III y IV posiblemente nos puede demostrar con más claridad lo que ha sido la transformación del cristianismo en ortodoxia. La ortodoxia se formó como cristianismo basado en la sabiduría del mundo en el sentido de San Pablo. Creo que se puede afirmar convincentemente que desde la interpretación de la crucifixión de Jesús que hace San Pablo y que se mantiene en los textos del mensaje cristiano, jamás podría haber surgido el antijudaísmo agresivo que surgió desde la ortodoxia cristiana. Las razones de la crucifixión no la disculpan. Sigue habiendo denuncia. Pero ésta no desata odios sino transformación, renovación, cambio de la manera de enfocar la realidad. Provoca para seguir el camino de Jesús. Es lo que Ilaman en este tiempo metanoia. Hay razones de lo que ocurre y para transformar hay que enfrentar las razones. Pablo no culpabiliza, sino llama a la transformación. Por eso no llama al odio.

Pero para San Pablo se trata de una "sabiduría de Dios, misteriosa, escondida, destinada por Dios desde antes de los siglos para gloria 
nuestra", es decir, es Dios mismo en su eternidad en cuanto es sabiduría.

Nuestra gloria: gloria Dei vivens homo, vivens pauper. El Señor de la gloria es el Señor de nuestra gloria. Y la gloria —nuestra y de Dios- es: vivens pauper.

Porque a nosotros nos lo reveló Dios por medio del Espíritu; y el Espíritu todo lo sondea, hasta las profundidades de Dios. 1 Cor. 2,10

$Y$ nosotros no hemos recibido el espíritu del mundo, sino el Espíritu que viene de Dios, para conocer las gracias que Dios nos ha otorgado, de las cuales también hablamos, no con palabras enseñadas por la sabiduría humana, sino enseñadas por el espíritu, expresando realidades espirituales en términos espirituales. El hombre naturalmente no acepta las cosas del Espíritu de Dios; son locura para él. Y no las puede entender, pues solamente espiritualmente pueden ser juzgadas. En cambio, el hombre de espíritu lo juzga todo; y a él nadie puede juzgarle. 1 Cor. 2, 12-15

Ve desde lo que no es para llegar a la verdad. Hablar en términos espirituales parea expresar realidades espirituales es hablar desde lo que no es sobre lo que es. Aunque
San Pablo no lo diga expresamente, lo que no es, es lo que en los evangelios posteriormente se Ilama el "reino de Dios".

¡Nadie se engañe! Si alguno entre vosotros se cree sabio según este mundo, vuélvase loco, para llegar a ser sabio; pues la sabiduría de este mundo es locura a los ojos de Dios. 1 Co.r 3,18-19

En la misma carta dice después: Ahora vemos en un espejo, en enigma. Entonces veremos cara a cara. 1 Cor 13,12 En el espejo vemos lo que es, pero no vemos, lo que no es, es este cara a cara entre uno y otros (Marx: relaciones directas entre la personas) Ver desde lo que no es, es la sabiduría de Dios que se descubre en el espíritu. Es la vista de la verdad. Inclusive: y el Espíritu todo lo sondea, hasta las profundidades de Dios. 1 C 2,10 En el cara a cara se revelan las profundidades de Dios. Se revelan como lo que no es. 
Yo estuve en mi juventud (1949-1950) un año en un noviciado jesuita. Recuerdo una discusión con el pater magister de nombre Flosdorf, cuando este citaba a San Ignacio diciendo: si tengo la opción de convertir al capitán de una tropa o al soldado raso, voy a convertir al capitán. Eso, porque si tengo al capitán, tengo toda la compañía. Yo protesté, insistiendo que habría que escoger al soldado raso, porque a partir del soldado raso se da la luz de la Buena Nueva. El pater magister me contestó: En el fondo Usted tiene razón con su crítica, pero hay que entender a San Ignacio desde su tiempo. Yo estaba de acuerdo, y sigo de acuerdo hoy. Pero siempre insistiría: esta proposición de San Ignacio es de sabiduría de este mundo, no presenta la sabiduría de Dios. La sabiduría de Dios es sabiduría loca, enfrenta al cálculo de la utilidad. Este cálculo es del orden de: es útil, visto desde el cálculo de la utilidad y del poder, de lo cual se deriva, que es necesario. Borra la sabiduría de Dios. San Ignacio, en cambio, en este juicio, somete todo al cálculo de utilidad. Esta historia verdadera muestra el problema de la ortodoxia cristiana con su sabiduría del mundo, pero muestra igualmente su relativa permeabilidad.

Hoy los historiadores suponen, que San Pablo fue entregado a las autoridades romanas para su ejecución por un grupo de cristianos. Se los Ilama los judaizantes. El nombre revela la mala intención apologética. De hecho, fue declarado hereje por estos cristianos, y es el primer hereje entregado al brazo secular de la autoridad mundana para ser ejecutado. Leyendo los primeros capítulos de la primera carta a los corintios, no hay duda por qué.

\section{El juego de locuras de nuestro tiempo}

E I juego de locuras es llevado por San Pablo al nivel de una argumentación sobre la base de paradojas. De otra manera no podría mostrarla. Estas paradojas vuelven a aparecer, y también han aparecido antes. Hay un antiguo filósofo chino, que muestra ya este mismo juego de las locuras. Se trata de Chuang-Tzu ${ }^{8}$, que vivió hace alrededor de 2,200 años. En él la sabiduría de Dios se llama el Tao. Es muy parecida a la percepción paulina de la sabiduría de Dios, aunque no sea lo mismo. Para él también existe el lugar de lo que no es, pero desde el cual se puede saber lo que es.

Ha sido el lenguaje de los dadaístas, que desemboca también en paradojas. Picabia, uno de los miembros del grupo de los dadaístas, decía: lo indispensable es inútil. ¡Eso es locura divina! Allí está contenido el problema del lenguaje: palabras enseñadas por la 
sabiduría humana y el lenguaje, que expresa realidades espirituales en términos espirituales. Es el lenguaje que habla sobre y desde lo que no es, y no desde lo que es. Por tanto, tiene que hablar en parábolas o paradojas. Es el lenguaje de las paradojas, que excava lo espiritual. Es el lenguaje de los dadaístas que otra vez lo utiliza otro dadaísta, Hugo Ball: el lenguaje como la cárcel de la poesía. Se trata del lenguaje destruido por la elaboración del lenguaje como simple transferencia de mensajes informativos, que es un lenguaje reducido al servicio del propio cálculo de utilidad. Es el lenguaje perfecto concebido como un lenguaje sin ambivalencias, que destruye no solamente la poesía, sino cualquier sabiduría. Destruye hasta la sabiduría de este mundo y no deja más que un esqueleto o "juegos del lenguaje". La paradoja de Ball es ahora: la poesía tiene que decir por medio del lenguaje lo que el lenguaje no puede decir.

Es también el lenguaje del cinismo de Diógenes, que aparece en los evangelios: p.e. la entrada triunfante de Jesús en Jerusalén. La hace sobre un burro, animal impuro según la creencia judía. Es lenguaje espiritual -a partir de lo que no es-que deja al emperador desnudo. Es locura que revela locuras.

Cuando Marx habla de Hegel, dice que está puesto de cabeza y que hay que ponerlo sobre sus pies $^{9}$. No habla de locura, como lo hace San Pablo, pero se trata del mismo juego. San Pablo también podría haber dicho que la sabiduría del mundo está puesta de cabeza, por tanto está loca (dislocada). Algo así ocurre también, cuando Marx dice: Un fantasma recorre Europa: el fantasma del comunismo. La palabra fantasma sustituye la palabra locura. Se refiere a lo que ven los poderes de su mundo. Ven locura y fantasma. Entonces Marx habla del comunismo como fantasma. Se refiere a lo que ven los otros.

San Pablo podría haber dicho en su tiempo: Una locura recorre el imperio: la locura divina.

Efectivamente, se trataba de una locura hasta en las propias palabras de San Pablo. Después, con la imperialización del cristianismo, éste abandonó la locura. La ortodoxia, que surge, deja de ser locura y es ahora sensata y muy razonable. Lo hizo como se hizo sensata la Ifigenia de Eurípides. Hasta el Papa Ratzinger puede encontrarse con el presidente Bush para un paseo armonioso en los jardines del Vaticano.

Sin embargo, esta misma iglesia es incapaz de entender al entender el caso de Monseñor Romero, asesinado cuando celebraba la misa. Es demasiado sensata. Romero hizo el siguiente Ilamado a los soldados de El Salvador: 
Ningún soldado está obligado a obedecer una orden contra la ley de Dios. Una ley inmoral nadie tiene que cumplirla. Ya es tiempo de que recuperen su conciencia y que obedezcan antes a su conciencia que a la orden del pecado. / En nombre de Dios, pues, y en nombre de este sufrido pueblo cuyos lamentos suben hasta el cielo cada día más tumultuosos, les suplico, les ruego, les ordeno: ¡cese la represión!

Eso es la locura divina a través de la cual habla la sabiduría de Dios. Vista desde la sabiduría del mundo es un crimen que merece la condena de muerte.

La iglesia institucional no sabe que hacer frente a figuras como Romero o el grupo de jesuitas asesinados por el gobierno salvadoreño en 1989. Tiende más bien a interpretar el asunto como consecuencia del hecho de haberse metido en política. Por tanto, no los reconoce como mártires, en cuanto su muerte no ocurre por un asunto "religioso". Estas iglesias no conocen lo que San Pablo llama la "locura divina". Se han hecho "sensatas".

Este crimen de Romero también cometió Dietrich Bonhoeffer y tantos otros, que incluyen a los comunistas y socialistas, que se enfrentaron al nazismo, también Rosa Luxemburg, Gandhi, Martin Luther King y fueron matados. También pertenecen a ellos el Che Guevara y Camilo Torres. Nadie de ellos se sacrificó: son testigos de su locura divina, a través de la cual habla la sabiduría de Dios.

Es locura divina, camino a la sabiduría de Dios, que el mundo condena a la muerte.

Hoy hace falta: Una locura recorre el mundo. La locura divina del yo soy si tú eres.

Es la locura que lo hace a uno sabio hoy.

¿Y qué es esta locura? Para repetir:

Ha escogido Dios más bien a los locos del mundo para confundir a los sabios. Y ha escogido Dios a los débiles del mundo para confundir a los fuertes. Lo plebeyo y despreciable del mundo ha escogido Dios; lo que no es, para reducir a la nada lo que es. 1 Cor 27-28 
... desemboca en la doctrina de que el hombre es el ser supremo para el hombre $y$, por consiguiente, en el imperativo categórico de echar por tierra todas las relaciones en que el hombre sea un ser humillado, sojuzgado, abandonado y despreciable ${ }^{10}$.

Por tanto, desemboca también en la exigencia que el análisis de la realidad tiene que hacerse bajo el punto de vista de lo que no es, y no a partir de lo que es ${ }^{11}$. Solamente así puede revelar la verdad.

También es locura divina. También se perdió en la formulación de la ortodoxia marxista y hace falta recuperarla.

Dostoyevski, cuando escribe un libro sobre Jesús, aunque en clave, lo Ilama: El idiota. Jesús como idiota, cuando está visto desde el poder. Y cuando escribe su parábola del Gran Inquisidor, muestra un cristianismo que abandonó las idioteces y que se hizo sensato al aliarse con el poder. En la parábola Jesús salva su vida. La salva por retirarse del mundo y entregarlo a los inquisidores.
También Bartolomé de Las Casas es un idiota en este sentido, y el libro de Gustavo Gutiérrez lo muestra magistralmente ${ }^{12}$. Tuvo la suerte de no ser entregado al brazo secular del poder del mundo para su ejecución. Eso en una situación, en la cual el cristianismo vino a América para bautizar, no para predicar la Buena Nueva. La Nueva que trajo, era una Mala Nueva. Pero bautizaba.

El escritor Vargas Llosa escribió hace no mucho el prólogo para un libro editado en América Latina con el título El Manual del perfecto idiota $^{13}$.

En la Unión Soviética estos idiotas iban al manicomio. Son los mismos idiotas. $\mathrm{Y}$ muchas veces tienen que ver directamente con el idiota de Dostoyevsky.

\section{El juego de locuras y el maniqueísmo}

sta polarización no es de por - sí maniqueísmo, sino la explicación de su surgimiento. Hay una polaridad en el interior de la realidad, frente a la cual hay que comportarse. No es simplemente una invención, sino que surge de la realidad misma. Es una explicación 
de hechos: el hecho, de que se produce este juego de locuras, una vez que aparece la sabiduría de Dios con su criterio de verdad.

Es imposible que esta polarización no aparezca. En este sentido el análisis de San Pablo es explicativo. Pero si es inevitable, aparece el problema: ¿cómo comportarse frente a esta polarización? Es la pregunta por las mediaciones. San Pablo no la contesta. La pregunta que hacía falta no la hace: ¿Cómo disolver esta polarización? ¿Cómo transformarla en una relación conflictiva que se resuelve constantemente sobre la base del reconocimiento mutuo relativo de ambas posiciones? Las Ilamadas a la tolerancia son simple moralina. Hay que mostrar que ambas posiciones tienen una raíz racional, aunque en el curso de imposición ciega se transforman en irracionalidades locas. La una se transforma -míticamente hablando- en Satanás, la otra, en el demonio Lucifer. Solamente el reconocimiento mutuo de la raíz racional de ambas posiciones permite desinflar esta polarización. Ninguna puede ser loca en su raíz y no lo es. Aunque sean locuras, tienen raíz racional. Míticamente expresada, la relación es entre lo satánico y lo luciférico (y no entre lo apolínico y lo dionisíaco $)^{14}$.

Al no desarrollar las mediaciones que corresponden, San Pablo constantemente desemboca en grandes ambigüedades. Son las ambigüedades del cristianismo pos- terior y de las propias sociedades seculares, que le siguen en la modernidad. Cada uno de los polos se pueden legitimar. Pero al legitimar en términos absolutos uno frente al otro, aparecen los polos satánicos y luciféricos.

San Pablo piensa desde experiencias suyas. Son todas experiencias en pequeña escala. La experiencia de Atenas y la del conflicto en Corintio son casos notables, pero así es toda experiencia humana. En el microcosmos está escondido el macrocosmos. Por lo tanto se habla del macrocosmos a partir del microcosmos. Todos de hecho hacemos eso, no hay otra manera de vivir lo que pasa en el macrocosmos. En San Pablo eso es Ilamativo: descubre lo que es el macrocosmos a partir del microcosmos, por la razón sencilla de que siempre el macrocosmos está en el microcosmos como el microcosmos está en el macrocosmos.

Es lo que pasa con la vida y muerte de Jesús en Palestina y Jerusalén. La Jerusalén de este tiempo es periferia del mundo, sin ninguna importancia en el imperio, pero este microcosmos revela el macrocosmos y lo transforma. En lo pequeño está la fuerza. Y lo que determina no está en el poder de Roma, ni entonces ni hoy.

San Pablo sabe ver el macrocosmos en el microcosmos, porque en lo pequeño está lo grande y en lo débil está la fuerza. Es lo que llama sabiduría de Dios. 
Lo que es Nueva York se ve en Harlem y el Bronx, no en Manhattan y su bolsa. Tampoco se lo ve en Hollywood. Lo que pasa en Europa, se ve en la legislación europea sobre los inmigrantes, con su consecuencia de nuevos campos sin ley y los muertos africanos en el mar, y lo que es la estrategia de la globalización se ve mejor en África y en Haití y otros países del Tercer Mundo. La sabiduría de Dios juzga a partir de allí. Escuché a un africano decir en un congreso: África no es el problema, África es la solución. Puede ser cierto. Por lo menos vale: si no hay solución para África y desde África, no se trata de una solución. Todo eso lo vemos diariamente en el Gulag del mundo libre, que se extiende por los barrios de miseria del mundo entero. En este Gulag encontramos la verdad de lo que es la estrategia de globalización. Es su base corporal.

¿Qué es la locura de la sabiduría de este mundo? No es irracionalidad de por sí. Es la irracionalidad de lo racionalizado. La crítica no niega esta racionalidad de por sí, sino que descubre en su interior la irracionalidad: quien busca la vida por el cumplimiento de la ley, encuentra la muerte.

En su carta a los romanos, San Pablo vuelve a hablar de esta locura. Con eso indica que sigue continuando su argumento de los primeros capítulos de la primera carta a los corintios:

En efecto, la cólera de Dios se revela desde el cielo contra la impiedad y la injusticia de los hombres que aprisionan la verdad en la injusticia: Rom., 1,18. Jactándose de sabios se volvieron locos: Rom. 1,22

Eso es lo que podríamos Ilamar la definición de la ideología — aunque San Pablo, por supuesto, no usa esta palabra- de parte de San Pablo: la injusticia aprisiona la verdad, la lleva presa, la atasca. El mismo concepto está presente en Marx. De hecho, podríamos sintetizar la carta a los Romanos por esta proposición. Todo se desarrolla a partir de eso. Ahora la locura de la sabiduría del mundo es este aprisionamiento de la verdad por la injusticia ${ }^{15}$. Es ideología. Se trata de la primera vez que el problema de la ideología es analizado.

También ir a bautizar en vez de dar la Buena Nueva, aprisiona la verdad en la injusticia.

Esta irracionalidad de lo racionalizado es la irracionalidad interior al cálculo de la utilidad. Consiste en "aprisionar la verdad en 
la injusticia" ¿Qué es la locura de la sabiduría de Dios? Es la razón, que trasciende la racionalidad de la sabiduría de este mundo en cuanto a su irracionalidad y lo efectúa en nombre del lo que no es. Desde el punto de vista de la sabiduría de este mundo, que no reconoce la irracionalidad en su propio interior, la razón de Dios es irracionalidad pura. Eso, porque la razón de Dios no puede argumentar por la razón instrumental, discursiva. Opera en el campo de la razón mítica. Puede argumentar solamente trascendiendo la razón instrumental.

Pero igualmente puede desarrollar su propia irracionalidad al pasar por encima de todas las factibilidades humanas en su intento de realización. Lo que se polariza es lo satánico del poder y lo luciférico de la liberación, el cálculo de utilidad - a partir del cual se constituye el poder-y la afirmación del otro: yo soy si tu eres.

Pero la polarización no es mediatizable por una simple conciliación entre polos de una antinómia. Tiene un lado que expresa la verdad de la sabiduría de Dios y que es la verdad también del otro polo, que es el polo de la sabiduría del mundo $y$, por tanto, del poder. Pero la sabiduría de Dios no puede abolir o sutituir el polo de la sabiduría del mundo. Por eso tiene que mediatizar, para poder ser el polo de la determinación y especificación legítima del todo. No es lo que Žižek Ilamaría un paralaje. La mediación resulta ser un conflicto tan inevitable y tan interminable como la propia condición humana, pero inscrito en un consenso sobre las propias razones del conflicto. El surgimiento de los dos polos hay que entenderlo como una escisión interna de la propia racionalidad de la acción humana, que es inevitable y de la cual se deriva la escisión de Dios como Dios del poder y Dios de la liberación. Podemos usar aquí un concepto, que creó Althusser, aunque lo cambiemos en su contenido. Se trata de la sobredeterminación. La acción humana tiene que sobredeterminar el conjunto de los conflictos desde la sabiduría de Dios. De esta manera puede ser emancipatoria. No reduce los conflictos a conflictos de intereses desnudos, sino los sobredetermina y penetra por el criterio de lo que San Pablo Ilama la sabiduría de Dios, que es locura divina frente a la sabiduría del mundo.

Cuando ocurre la negación mutua de un polo hacia el otro, esta se expresa también en el pensamiento. Al descubrir la irracionalidad en el interior de la racionalidad formal, Marx habla de ciencia burguesa. La ciencia burguesa, que niega esta irracionalidad, en cambio descubre pura irracionalidad en el otro polo. No responde al reproche de ser ciencia burguesa diciendo que lo que hace Marx es ciencia socialista. Por tanto sostiene, que el análisis marxista no es ni teoría, sino bla-bla, como lo sostiene Popper en términos más nítidos: no 
es científica. Por eso al reproche de ciencia burguesa de parte de Marx responde que lo que hace Marx ni es ciencia, sino un cúmulo de afirmaciones circulares. La condena de parte de Popper es total y, por tanto, el conflicto que corresponde. La condena de parte de Marx es relativa. Por tanto, permite un conflicto con mediaciones, aunque no se haya desarrollado todavía. Hoy, los nuevos gobiernos de izquierda en América Latina están intentando desarrollarlo. Pero la lógica de esta ciencia burguesa, al no admitir este desarrollo, desemboca en el nihilismo y el aniquilamiento. Es por negar que el otro tenga razones. Aunque se considere algo una locura, siempre hay que advertir, que también la locura tiene raíces en alguna razón.

\section{El laberinto de la modernidad}

C i buscamos el paradigma de la modernidad, es este: Resulta ser un laberinto. Contiene una gran estructura mítica, que es su sostén. Su argumentación tiene razones, pero son razones míticas, que engloban las razones instrumentales, que se desarrollan en su interior. En este sentido el paradigma es el marco categorial de la propia modernidad. Este marco categorial es y puede ser solamente mítico, es razón mítica.

Se trata de hecho de la irrupción de la referencia a un sujeto universal, que se enfrenta a todas las estructuras del mundo humano. Irrumpe y lo polariza. Pero lo que aparece no es alguna esencia externa que se introduce en la realidad. Aparece un quiebre en la realidad misma, que antes no es percibido. Por eso, lo que aparece, es un laberinto, dentro del cual se busca caminos. El laberinto es ahora el mundo mismo, sin poder salir de él.
Se vive en él, se sobrevive en él y se busca sobrevivir y moverse de la manera más humana posible. El hilo de Ariadna en este laberinto es la recuperación constante de lo humano.

Partimos del esbozo del paradigma de este laberinto en nuestro análisis de los textos de San Pablo. Sin embargo, este paradigma es algo que subyace al proceso histórico posterior. Los polos, en cambio, se desarrollan, aunque el paradigma vuelve y vuelva a subir, aunque las palabras cambien. Desde este paradigma se descubre el mundo como un mundo secular. La palabra secularización no se adecua bien a lo que es este proceso. No se trata de una secularización, sino del descubrimiento de la secularidad del mundo. La forma, en la cual Walter Benjamin lo enfoca, sigue siendo la más adecuada. Se trata de transformaciones, que se desarrollan desde el interior del proceso histórico concreto. 
Para mostrar el proceso en sus varias etapas históricas necesitaríamos un análisis mucho más detallado de lo que en este texto podemos ofrecer. Por eso, ni lo intento. Presento el análisis más bien

Notas

1 Este fragmento es publicado entero en Franz Hinkelammert: Hacia una crítica de la razón mítica. Editorial Arlekín, San José, Costa Rica, 2007 p.166-169

2 Walter Benjamin, Gesammelte Schriften, vol. II.1, Editado por Rolf Tiedemann e H. Schweppenhäuser, Suhrkamp, Frankfurt a.M. 1999

3 Goethe posteriormente cambia mucho su posición. En Fausto, él ve el asesinato de inocentes efectivamente como crimen (Filemón y Baucis)

4 Bernardo de Claraval: Liber ad milites templi de laude novae militiae. (Libro sobre las glorias de la nueva milicia. A los Caballeros Templarios.) Obras Completas de San Bernardo, BAC, Madrid 1983, 2 tomos. I, p.502

5 Así también se interpreta a Eva en el libro de Henoc:

Llegué al paraíso justo y vi, además de aquéllos, otros árboles que crecian alli, cuyo aroma era bueno. Eran grandes, excelentes y de mucha belleza, y vi el árbol de la ciencia, del que, si alguien come, adquiere gran sabiduría. Se parece al algarrobo, y su fruto es como racimo de uva, muy hermoso, y el aroma de este árbol sale y llega lejos. Dije:

-Qué hermoso es ese árbol, qué hermoso y ameno de aspecto! en el sentido de un esbozo de todo un programa de investigación. El fragmento citado de Benjamin Capitalismo como religión es también eso. Trato de tomarlo en serio y irlo ampliando.

$Y$ me respondió el santo ángel Rafael, que estaba conmigo. Me dijo:

- Este es el árbol de la ciencia, del cual comieron tu anciano padre y tu anciana madre, que te procedieron, adquiriendo sabiduría y abriéndoseles los ojos, de modo que advirtieron que estaban desnudos y fueron expulsados del Paraíso. Apócrifos del Antiguo Testamento. Tomo IV. Ciclo de Henoc. Ediciones Cristiandad. Madrid 1984. Libro 1 de Enoc, 28, 32 (p. 64)

Jesús entra también en este juego:

—iAy de vosotros, los legalistas ( $j u$ ristas: FJH), que os habéis llevado (lo ban quitado! se han "adueñado de": FJH) la llave de la ciencia! No entrasteis vosotros, $y$ a los que están entrando se lo habéis impedido. (Luc. 11, 52 Biblia de Jerusalén).

Las palabras entre paréntesis las saqué de otras traducciones.

El reproche es: Ustedes no han comido del árbol de la ciencia, e impiden que otros coman de él.

Volviendo al caso de Clitemnestsra: Clitemnestra tenía la llave de la ciencia, y Agamenón prohibe que entra. Al no aceptarlo Clitemnestra, ella es vista como loca.

Aunque en otro contexto, el mismo Aristóteles dice: No hay ningún gran genio sin una pizca de locura. 
7 Introduzco algunos cambios de la traducción en español de la Biblia de Jerusalén. Sobre todo traduzco Cristo siempre por Mesías (Cristo es la palabra griega por Mesías) y Evangelio por Buena Nueva.

8 Chuang-Tzu. Monte Ávila. Caracas, 1991

$9 \quad$ Eso mismo, con otras palabras, dice sobre la economía política clásica:

Esto no obsta para que los mejores portavoces de la economía clásica, como necesariamente tenía que ser dentro del punto de vista burgués, sigan en mayor o menor medida cautivos del mundo de apariencia críticamente destruido por ellos, e incurran todos ellos, en mayor o menor grado, en inconsecuencias, soluciones a medias y contradicciones no resueltas (Marx, El Capital, FCE III p. 768)

10 Fromm, Erich: Marx y su concepto del hombre. (Karl Marx: Manuscritos económico-filosóficos). FCE. Mexico, 1964. P.230

11 Vea la primera parte del artículo: Franz Hinkelammert: Sobre la reconstitución del pensamiento crítico. (véase en www.pensamientocritico. info)

12 Gutiérrez, Gustavo: En busca de los pobres de Jesucristo. El pensamiento de Bartolomé de Las Casas. Instituto Bartolomé de Las Casas. CEP. Lima, 1992

13 Plinio Apuleyo Mendoza, Carlos Alberto Montaner y Álvaro Vargas Llosa: Manual del perfecto idiota latinoamericano. Con Prólogo del escritor Mario Vargas Llosa.Editorial Atlántida Barcelona, 1996.

14 Para estas afirmaciones me baso en el libro: Hinkelammert, Franz: El asalto al poder mundial y la violencia sagrada del Imperio. DEI. San José, 2003

15 Hay hoy una amplia discusión sobre esta cercanía de San Pablo con el pensamiento marxista.

Ver:

-Agamben, Giorgio: Il tempo che resta. Un comento alla Lettera ai Romani. Bollati Boringhieri. Torino, 2000

-Badiou, Alain: Saint Paul. La fondation de l'universalisme, París, Presses Universitaires de France, 1997 (Ed. Cast.: San Pablo. La fundación del universalismo, Madrid, Anthropos, 1999

-Taubes, Jocob: La teología política de Pablo. Trotta. Madrid, 2008

-Žižek, Slavoj: El espinoso sujeto. El centro ausente de la ontología política. Paidós. Barcelona, 2001

-Žižek, Slavoj: El frágil absoluto. ¿Por qué merece la pena luchar por el legado cristiano? PRE-TEXTOS. Valencia, 2000

-Žižek, Slavoj: El títere y el enano. El núcleo perverso del cristianismo. Paidós. Buenos Aires, 2005

-Žižek, Slavoj: Visión de paralaje. FCE. Buenos Aires, 2006

Ver también:

-Hinkelammert, Franz J.: Las armas ideológicas de la muerte. DEI, San José, 1981. Segunda Edición revisada y ampliada con introducción de Pablo Richard y Raúl Vidales.

-Tamez, Elsa: Contra toda condena. La justificación por la fe desde los excluidos. DEI. San Jose, 1991 